\title{
Draw your Heart Disease: A Graphic Assessment of the Knowledge of Congenital Heart Disease of Patients and their Parents
}

\section{Paula Mariño García ${ }^{1 *}$, Ángeles Fuertes Moure ${ }^{2,3}$, Isaac Martínez Bendayán ${ }^{4}$, Vanesa Balboa Barreiro ${ }^{5,6}$ and Fernando Rueda Núñez ${ }^{3}$}

${ }^{1}$ Department of Pediatrics, Complejo Hospitalario Universitario de A Coruña (CHUAC), SERGAS, Spain

${ }^{2}$ María José Jove Foundation, A Coruña, Spain

${ }^{3}$ Department of Pediatrics, Section of Pediatric Cardiology, Complejo Hospitalario Universitario de A Coruña (CHUAC), SERGAS, Spain

${ }^{4}$ Department of Cardiology, Complejo Hospitalario Universitario de A Coruña (CHUAC), SERGAS, Spain

${ }^{5}$ Research Support Unit, Institute of Biomedical Research of A Coruña (INIBIC), Complejo Hospitalario Universitario de A Coruña (CHUAC), SERGAS, Spain

${ }^{6}$ Hospital Materno Infantil de A Coruña, Complejo Hospitalario Universitario de A Coruña, Spain

*Corresponding author: Paula Mariño García, Department of Pediatrics, Complejo Hospitalario Universitario de A Coruña (CHUAC), SERGAS, Spain Cornes 50, 15706 Santiago de Compostela, Spain, Tel: 0034-669370362

\section{Abstract}

Introduction: Patients with congenital heart disease are a chronically ill population. Knowledge of the disease is a key factor in promoting an appropriate attitude towards health. The aim of this study is to evaluate the understanding of heart involvement by describing the heart disease and drawing a picture of the heart by patients and parents.

Materials and methods: Descriptive cross-sectional study over an 8-month period in a tertiary pediatric cardiology center, involving 201 parents and 123 patients, of whom 74 were between 8 and 14-years-old and 49 were older than 14-years-old. A questionnaire was used in which they had to name and describe the disease, and where a blank box was included in which they were asked to draw their congenital heart disease.

Results: $68.8 \%$ of the patients correctly named their heart disease, however only $32.4 \%$ described it adequately and only $3.5 \%$ drew a correct picture of it. Divided by age groups, of the patients between 8 and 14 -years-old $45.9 \%$ named their cardiopathy correctly, $28.2 \%$ described it adequately and $4.1 \%$ drew a correct picture of it. Of those over 14 years of age, $83.6 \%$ correctly named their cardiopathy, $26.5 \%$ knew how to describe it and only $2 \%$ managed to draw it properly. In the group of parents, $79.1 \%$ correctly named their child's congenital heart disease, $45.8 \%$ described it adequately and only $3.5 \%$ drew a correct picture ( $p$ value 0.55 ).
\end{abstract}

Conclusions: Most parents and patients with congenital heart disease are unaware of fundamental aspects of their heart disease. An effort should be made by the professionals to try to explain congenital heart disease in an illustrative way, in order to achieve a better understanding of the disease and thus optimize the behavior in terms of health.

\section{Keywords}

Congenital heart disease, Parents, Teenagers, Knowledge, Drawings, Quality of life

\section{Abbreviations \\ CHD: Congenital Heart Disease}

\section{Introduction}

Children with congenital heart disease (CHD) represent about $1 \%$ of live newborns [1]. Due to advances in pediatric cardiac care, they are a growing population. In recent decades, survival of patients with CHD has increased dramatically and studies have moved from a focus on survival only to broader functional and quality of life assessment. Today it is estimated that

Citation: García PM, Moure AF, Bendayán IM, Barreiro VB,Núñez FR (2021) Draw your Heart Disease: A Graphic Assessment of the Knowledge of Congenital Heart Disease of Patients and their Parents. Int J Clin Cardiol 8:243. doi.org/10.23937/2378-2951/1410243

Accepted: December 01, 2021: Published: December 03, 2021

Copyright: (c) 2021 García PM, et al. This is an open-access article distributed under the terms of the Creative Commons Attribution License, which permits unrestricted use, distribution, and reproduction in any medium, provided the original author and source are credited. 
$85 \%$ of children with CHD will reach adulthood, and many of them will do so with some residual defect, thus becoming chronically ill patients [2].

However, survival does not guarantee good functional capacity or an adequate quality of life. Postoperative children and adults present a progressive decrease in functional capacity that affects their physical, social, emotional, educational, occupational and cultural development, which results in a worsening of their quality of life and an increase in morbidity and mortality [3].

For all these reasons, studies focused on evaluating the functional aspect of patients with CHD have currently gained special interest, as well as many others aimed at evaluating health-related quality of life $[3,4]$.

Knowledge of the disease is a key factor in promoting an appropriate attitude towards health, and therefore there is a direct relationship with health-related quality of life. As with other chronic diseases, parents and patients with $\mathrm{CHD}$ need information about their disease and the risks of morbidity and mortality. In this way, adequate knowledge of the disease can help to adopt a healthy lifestyle [5].

It is important to stress that in the case of the paediatric population, both the patients themselves, children or adolescents, and their parents should adequately understand their disease and its possible implications. Adequate knowledge of their children's CHD will allow parents to transmit this knowledge in the future and develop appropriate educational guidelines. However, as reported in the literature [6], it is frequent that parent does not understand the information trans-mitted by medical staff or that this information is eventually forgotten.

In this sense, it is also of special interest to study the knowledge of the disease itself during the period of adolescence [7], given that this is a stage of transit of the child to adulthood and therefore, the teenager himself must become aware of the care of his health.

The main objective of this study is to evaluate the understanding of heart disease in children, adolescents and adults with CHD and also their parents, evaluated in a descriptive and graphic way. The secondary objective is to elucidate differences in terms of gender and CHD complexity.

\section{Materials and Methods}

This is a descriptive cross-sectional study aiming on the understanding of heart disease of 123 patients with congenital heart disease $(49 \%$ girls, mean age 13.02 years, range $8-55$ years) and their 201 parents. The patients suffered from CHD such as: Isolated aortic or pulmonary stenosis, ventricular septal defects, Tetralogy of Fallot and transposition of great vessels, single ventricle or coarctation of the aorta.
The study took place over eight month period in a tertiary pediatric cardiology center. It was carried out on the basis of on an anonymous questionnaire prepared by the authors of this document. Once it was handed in at the follow-up con-salutations of Pediatric Cardiology and Adult Congenital Heart Disease, it was covered on a voluntary basis, having previously attached an information sheet to the participants and legal representatives. The questionnaire was only given to the parents of patients with CHD of paediatric age or to those who carried out the follow-up in the Child Cardiology Consultation. The CHDs were classified according to the current recommendations [8] as simple or complex. Complex congenital diseases include those heart diseases classified as Moderate Complexity and Great Complexity according to the 2018 AHA guide [8]. Moreover, the group of patients was studied as a whole and then analyzed by dividing them into two age-groups: Group 1 ( 8 and 14 years) and Group 2 (14 years or older) because at the age of 14 patients in our hospital were discharged from pediatric cardiology consultation and evaluated in the adult cardiology consultation. Ethical approval was obtained from the Reference Research Ethics Committee of the study center.

\section{Questioners and drawing}

In brief, the participant were asked to write the name of the heart disease, briefly explain in writing what it was and draw the heart defect in a blank box (Figure 1). Afterward two independent reviewers (a pediatrician and a pediatric cardiologist) judged the answers. It was considered a correct drawing when the anatomy of the heart was drawn simply and the evaluators understood the heart defect they represented. A drawing was considered incomplete when the heart defect they wanted to represent was understood, but the heart anatomy was not correctly drawn. Incorrect drawing was present if none of these criteria were correctly represented.

\section{Sample size calculation}

A sample size of 200 parents was considered necessary to estimate an expected prevalence of $50 \%$ of good knowledge about their children's heart disease, allowing the results to be provided with $95 \%$ certainty and $\pm 7 \%$ accuracy. In turn, a sample of 120 patients was needed to estimate a prevalence of $50 \%$ of good knowledge about the heart disease suffered with 95\% certainty and $\pm 8 \%$ accuracy.

\section{Data analysis}

The qualitative variables were expressed as frequency $(n)$ and percentage. The association between qualitative variables was estimated by means of the Chisquare statistical test or Fisher's test. A significance level of $95 \%$ was considered $(\alpha=0.05)$. The statistical analysis was carried out with the IMB program SPSS Statistics 24. 


\section{TELL US ABOUT YOUR CONGENITAL HEART DISEASE}

Age:

Gender:

\section{What's the name of your congenital heart disease? What it is?}

- The name is .....

- It is ...

\section{2. ¿Where is the heart? Draw it in the box}
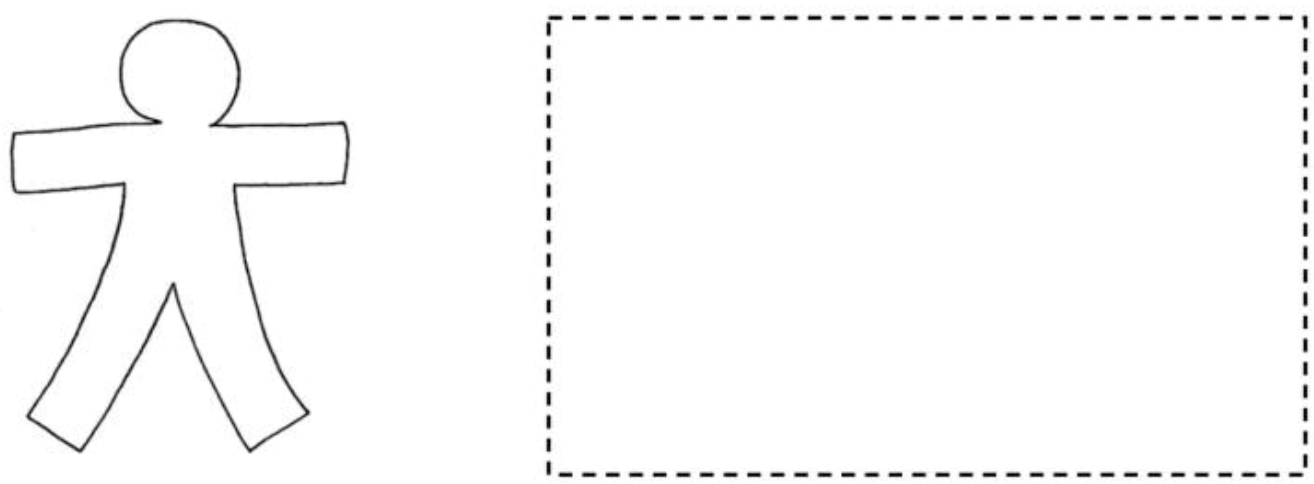

Figure 1: Questioner where the participant had to write the name of the heart disease, explain in writing what it was, locate the heart in the silhouette, and draw the heart defect in the blank box.

Table 1: Characteristics of the sample studied.

\begin{tabular}{|c|c|c|c|}
\hline & $\begin{array}{l}\text { Patients } \\
\text { 8-14 years-old } \\
(n=74)\end{array}$ & $\begin{array}{l}\text { Patients } \\
>14 \text {-years-old } \\
(n=49)\end{array}$ & $\begin{array}{l}\text { Parents } \\
(n=201)\end{array}$ \\
\hline & n (\%) & n (\%) & n (\%) \\
\hline \multicolumn{4}{|l|}{ Gender } \\
\hline Boy & $38(51.4)$ & $24(49.0)$ & \\
\hline Girl & $36(48.6)$ & $25(51.0)$ & \\
\hline \multicolumn{4}{|c|}{ Correct name of CHD } \\
\hline No & $40(54.0)$ & $8(16.3)$ & $42(20.9)$ \\
\hline Yes & $34(45.9)$ & $41(83.6)$ & $159(79.1)$ \\
\hline \multicolumn{4}{|c|}{ Understanding about CHD } \\
\hline No & $28(71.8)$ & $36(73.5)$ & $109(54.2)$ \\
\hline Yes & $11(28.2)$ & $13(26.5)$ & $92(45.8)$ \\
\hline \multicolumn{4}{|c|}{ Heart draws } \\
\hline Incorrect & $64(86.5)$ & $43(87.7)$ & $157(78.1)$ \\
\hline Incomplete & $7(9.5)$ & $5(10.2)$ & $37(18.4)$ \\
\hline Correct & $3(4.1)$ & $1(2.0)$ & $7(3.5)$ \\
\hline \multicolumn{4}{|c|}{ Type of congenital heart disease } \\
\hline Simple & $15(20.3)$ & $5(10.2)$ & $46(22.9)$ \\
\hline Complex & $59(79.7)$ & $44(89.8)$ & $155(77.1)$ \\
\hline
\end{tabular}

\section{Results}

The study involved 201 parents and 123 patients (49\% girls). Divided by age group, there were 74 patients aged $8-14$ years ( $48.6 \%$ girls) and 49 patients over 14 years $(51.0 \%$ girls). The oldest patient was 55 -years-old. The 123 patients were aged between 8 and 55 years and suffered from CHD such as: Isolated aortic or pulmonary 
stenosis, ventricular septal defects, atrial septal defects, Tetralogy of Fallot, and transposition of great vessels, single ventricle or coarctation of the aorta.

$68.8 \%$ of patients correctly named their heart disease. Group 2 patients showed a better knowledge of the name of their heart disease with respect to Group 1 ( $83.6 \%$ vs. $45.9 \%$ correct identification, p value 0.00 ). Of the parents, $79.1 \%$ knew the name of their child's heart disease.

$32.4 \%$ of the patients were able to correctly describe what the disease consisted of. In group 1 only $28.2 \%$ knew how to describe it adequately; this percentage was $26.5 \%$ in group 2 and $45.8 \%$ when described by the parents (Table 1). Some examples of answers to the question "What is your heart disease?" were:

- "It's a hole in the heart." (10-year-old boy with ventricular septal defect)

- "I was born with holes in my heart and now I have an umbrella" (7-year-old girl with closed atrial septal defect)

- "It's a narrowing of the aorta" (father of an 8-yearold girl with coarctation of the aorta)

- "He has changed veins" (father of 10-year-old boy with transposition of large vessels)

- "It's a blow" (father of a 9-year-old girl with severe pulmonary stenosis)

- "It's a congenital heart problem" (father of 12-year-old boy with Tetralogy of Fallot)

$86.1 \%$ of patients and $78.1 \%$ of parents drew a wrong picture (Figure 2, Figure 3, Figure 4 and Figure 5). $10.4 \%$ of the patients and $18.4 \%$ of the parents drew it incompletely (Figure 6 and Figure 7). Of the group of patients, only $4.1 \%$ (3 patients) of the children in group 1 , and $2.0 \%$ (1 patient) of group 2 drew a correct picture (Table 1). Only $3.5 \%$ of the parents drew their child's CHD correctly (Figure 8).

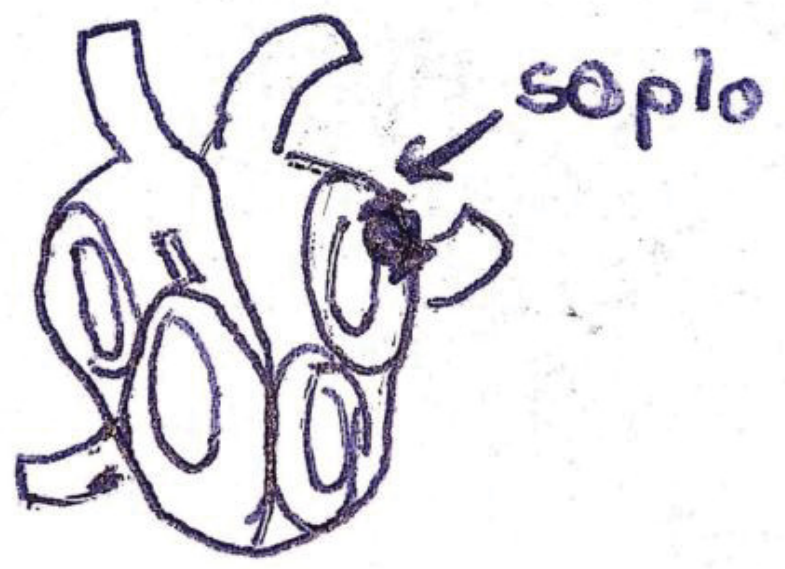

Figure 2: Incorrect drawing made by a 10-year-old boy with Tetralogy of Fallot.

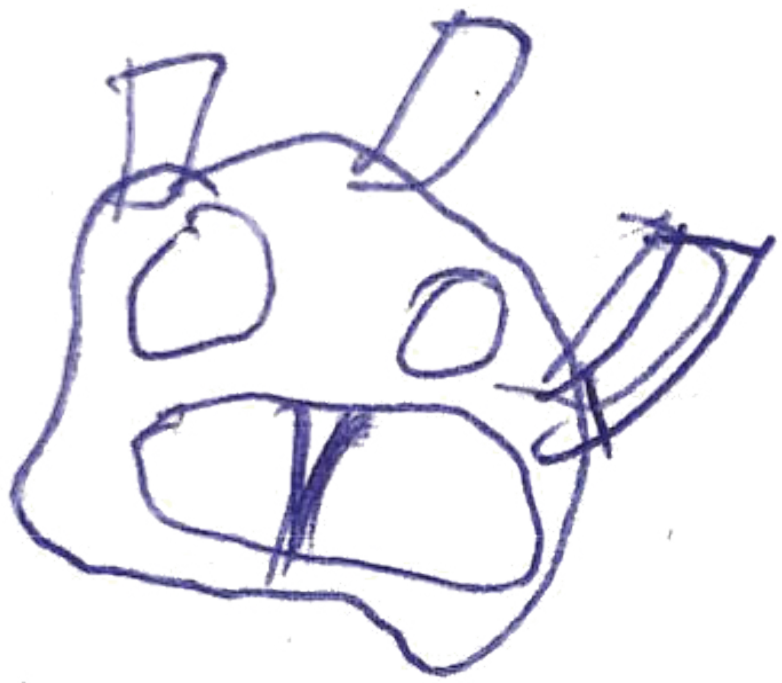

Figure 3: Incorrect drawing made by an 8-year-old father with pulmonary stenosis.

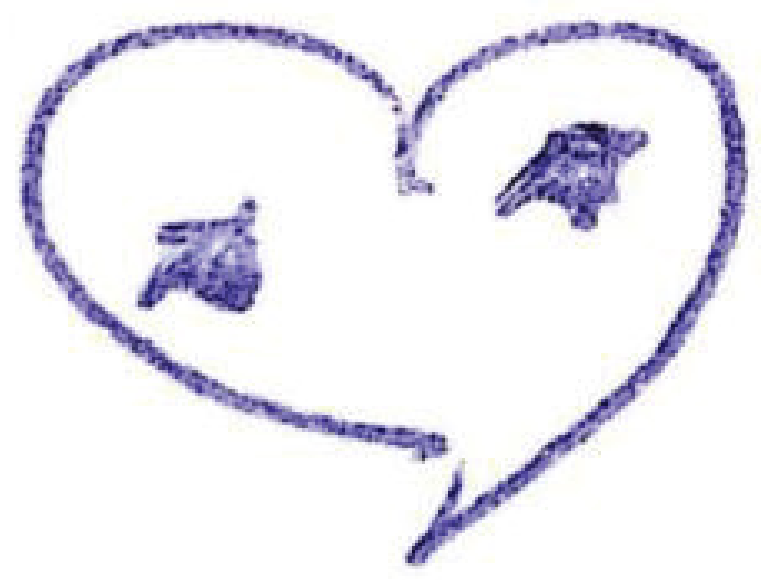

Figure 4: Incorrect drawing made by an 11-year-old boy with a ventricular septal defect.

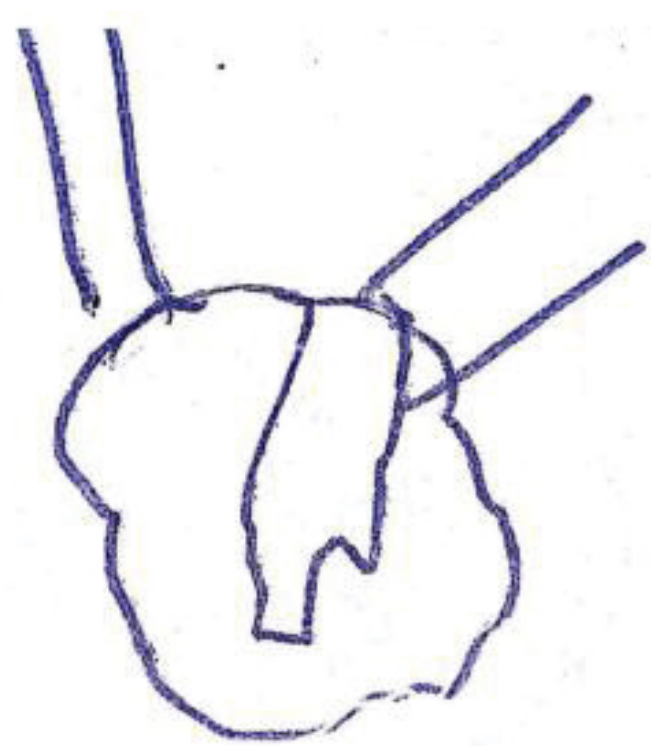

Figure 5: Incorrect drawing made by a 13-year-old girl with pulmonary atresia. 


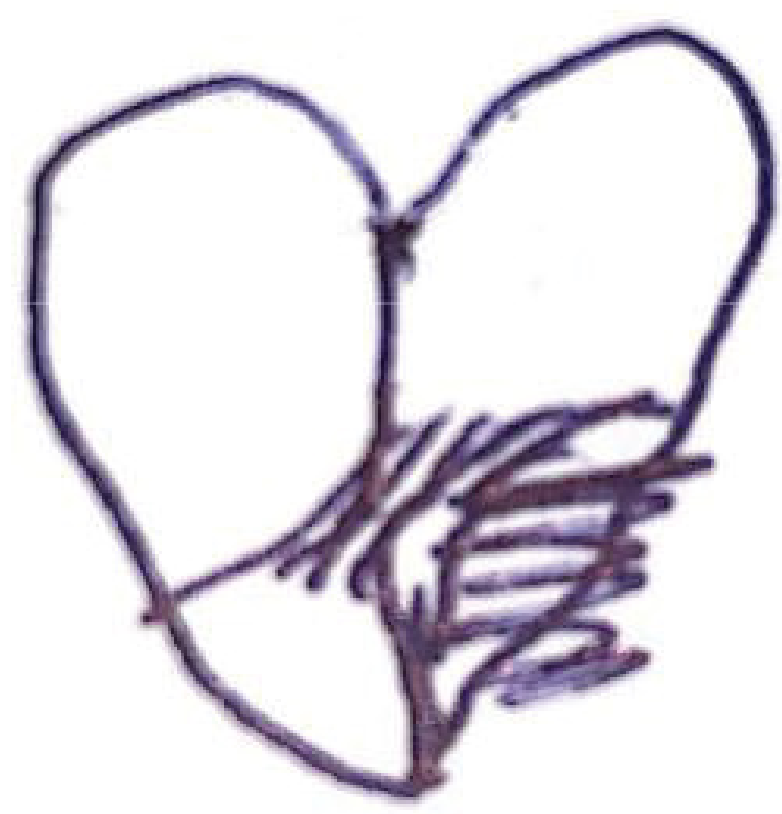

Figure 6: Partially correct drawing made by a 23-year-old patient with a single ventricle.

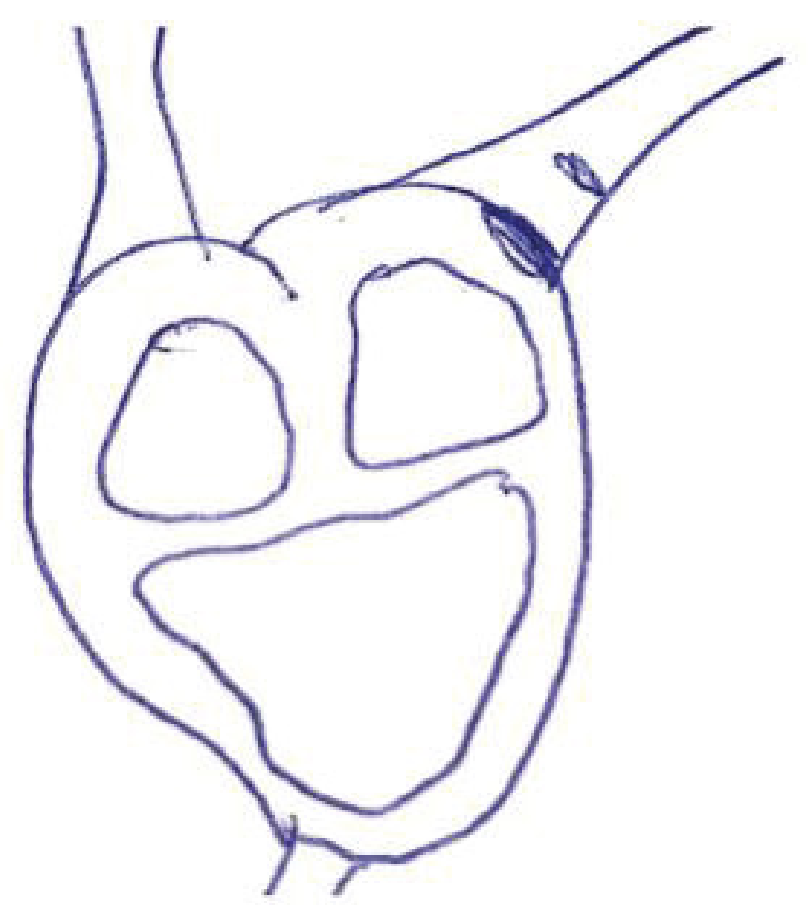

Figure 7: Partially correct drawing made by a parent of a 12-year-old boy with a ventricular septal defect.

\section{Gender analysis of patients}

Distributing the patients by sex, in group 1, 47.1\% of those who correctly named the heart disease and $36.4 \%$ of those who adequately described it were girls. On the other hand, in group 2,53.7\% of those who correctly named the cardiopathy and $53.8 \%$ of those who described it adequately were girls.

Assessing the way heart disease is drawn, boys drew it better regardless of age ( $p$ value 1.00).

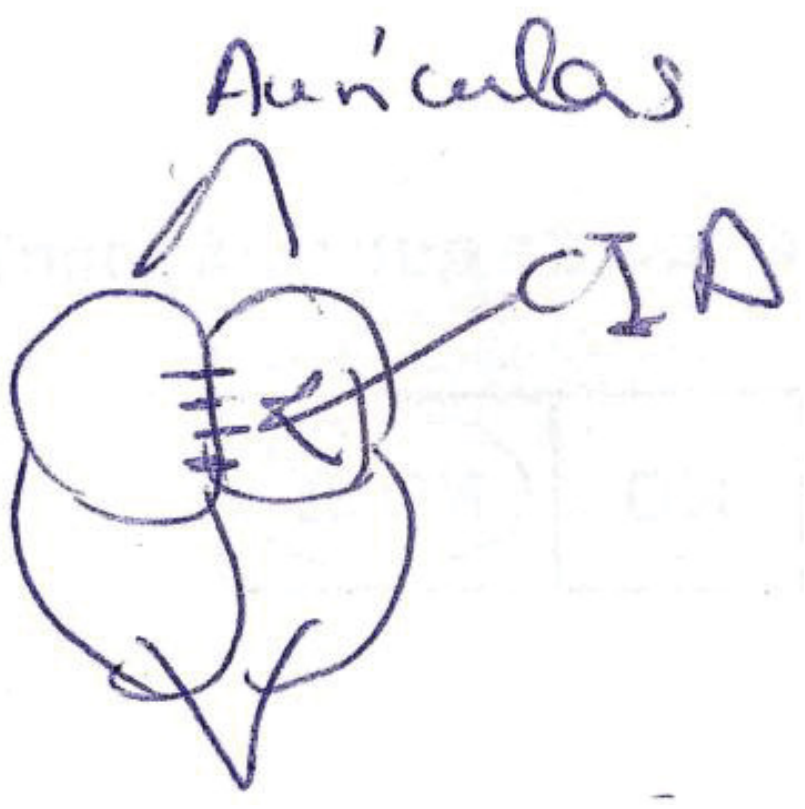

Figure 8: Correct drawing made by a parent of a 13-yearold boy with an atrial septal defect.

There was no difference in knowledge of their heart disease based on the sex of the patient ( $p$ value 0.442 ).

\section{Analysis by type of congenital heart disease}

In group 1 , only $17.6 \%$ of those who correctly named their heart disease had a simple CHD. However, $92.9 \%$ of the patients who did not understand their disease had a complex CHD, with statistical significance ( $p$ value 0.012 ). In the re-presentation by means of the drawing, $66.7 \%$ of those who drew their cardiac affectation well presented a simple CHD. In group 2, only $4.9 \%$ of those who named their congenital heart disease correctly had a simple congenital heart defect.

None of those who drew their CHD well had a simple congenital heart defect.

Of the parents, only $20.1 \%$ of those who named their child's heart disease correctly referred to a simple heart disease. The majority (81.5\%) of those who did not understand the disease presented a complex congenital heart defect. The $57.1 \%$ of those who made a correct drawing represented a simple congenital heart defect.

There were no differences in the knowledge of the disease according to the type of congenital cardiopathy.

\section{Discussion}

In this study, carried out on a sample of more than 300 patients and parents, we observed that the knowledge of congenital heart diseases is deficient, on the basis that most of them did not describe it adequately and almost all of them were unable to simply draw the heart defect. It has been described in the literature [9] that a good knowledge of the disease and its understanding in an optimal way is associated with lower stress figures, better emotional state, and greater satisfaction with 
health personnel and better compliance with therapy. For this reason, it is important to know the degree of knowledge of patients about their disease.

In the healthcare setting, it is common for the diagnosis of CHD to be explained in a simple manner and with understandable drawings. It is also normal clinical practice for this information to be repeated in successive consultations, but it is true that healthcare personnel often do not ensure that this information transmitted is properly understood.

The results of our study are to some extent comparable to those of previous research. Matley, et al. [10] in their study of children with CHD and their parents appreciate that knowledge about the heart defect is inadequate, and that many of them are unable to name the disease correctly. In line with their results, in our study, it was found that although the majority of patients (children, adolescents and adults) and their parents know the name of the heart disease, few are able to adequately describe what the disease consists of, and only a small percentage are able to represent it in a graphic way by making a drawing.

Another study by Wang, et al. [11] has simply demonstrated the poor knowledge of heart abnormalities when asked to ex plain the heart defect with a drawing. They observed that, although there are exceptions, the drawing process is generally consistent with the level of knowledge of the heart disease.

One group of special interest is adolescents, since this is a transitional stage to adulthood, where they must be responsible for their own health care. Increasingly, transition programmes are being developed to prepare adolescents for this, as some studies have shown [12]. A critical element in transition programmes is patient health education, to improve the level of awareness of their illness and increase the concern for adopting appropriate self-care behaviours. This will be influenced by the degree of maturity of each adolescent and their sense of responsibility.

In our study, we found that the age of the patients is an important factor when evaluating the knowledge they present about their disease, observing that as the patient gets older, they know more about their heart disease. This may be influenced by the fact that in the transition consultation from the paediatric to the adult stage, it is likely that greater efforts are made to explain to the patients themselves what their disease consists of, since in the field of child cardiology, information is occasionally directed at parents.

On the other hand, we have seen that patients with complex CHD know the name of their heart disease better than those with simple CHD. This may be related to the fact that more complex and unusual names attract more attention and are therefore more easily remembered, or that more emphasis was placed on explanation.
In addition, patients with complex congenital heart disease generally require a greater number of visits to the doctor and more interventions, so they end up becoming more familiar with the disease and therefore with its name. However, when it comes to evaluating the understanding of the disease, in a descriptive way and through the elaboration of a drawing, we have seen that, in general, both the patients themselves and the parents of those who have complex heart disease, are the ones who present the worst results when they have to show what they know about the pathology.

For all the above reasons, this study would support the need to educate patients from an early age, explaining to them what their disease consists of, and not only to their parents, using language adapted to the child, so that it can support their transition to an independent adult in the future. On many occasions, professionals assume that parents are the ones who should explain their illness to their children, but there are parents who, in order to protect their children, prefer not to know the extent of their pathology. Furthermore, many of the parents are not clear about the repercussion of heart disease on their children's lives, and cannot adequately transmit to them the knowledge that the professionals are trying to explain.

Wang, et al. [13] point out the importance of having an adequate knowledge of the disease, observing in their study, that a better knowledge of the cardiac anomaly improves the quality of life of the patients and reduces the psychological impact generated by the disease.

The present study shows methodological limitations that require the results to be interpreted with caution. There is no standardized instrument to assess knowledge of $\mathrm{CHD}$ in pediatric patients or their parents, so we have used a small non-validated questionnaire developed at the authors' own unit, initially as a quality control. Caution should be exercised when generalizing the results, since it is difficult to extrapolate the results being a study carried out in a single center, although the sample is large and it is a national reference center for the treatment and monitoring of $\mathrm{CHD}$ at the time of the study.

\section{Conclusions}

Therefore, after the results obtained from the present study, we conclude that overall there is inadequate knowledge of the congenital heart disease by the patients and their parents. We believe that an effort should be made by professionals to try to explain congenital heart disease in an illustrative manner in order to achieve a greater understanding of the disease and thus optimize behavior in terms of health.

\section{Declarations}

\section{Ethics approval and consent to participate}

A Coruña-Ferrol Ethics Committee approved this 
study and the committee's reference number was 2019/403. Verbal consent was obtained from patients and from parents for participants under 16-years-old. This was approved by the ethics committee.

\section{Consent for publication}

Not applicable.

\section{Availability of data and material}

Not applicable.

\section{Competing interests}

The authors declare that they have no competing interests.

\section{Formatting of funding sources}

This research did not receive any specific grant from funding agencies in the public, commercial, or not-forprofit sectors.

\section{Author contributions statement}

PM: data collection and interpretation of data analysis, and critical revision of article; AF: concept or design of article and critical revision of article; IM, FR: critical revision of article and approval of article; VB: data analysis and statistics.

All authors have read and approved the manuscript.

\section{Acknowledgements}

Not applicable.

\section{References}

1. Rosamond W, Flegal K, Friday G, Furie K, Go A, et al. (2007) Heart disease and stroke statistics - 2007 update: A report from the American Heart Association Statistics Committee and Stroke Statistics Subcommittee. Circulation 115: e69-e171.

2. Triedman JK, Newburger JW (2016) Trends in congenital heart disease: The next decade. Circulation. 133: 27162733.
3. Amedro P, Picot MC, Moniotte S, Dorka R, Bertet $H$, et al. (2016) Correlation between cardio-pulmonary exercise test variables and health-related quality of life among children with congenital heart diseases. Int J Cardiol 203: 10521060.

4. Ladak LA, Hasan BS, Gullick J, Gallagher R (2018) Healthrelated quality of life in congenital heart disease surgery in children and young adults: A systematic review and metaanalysis. Arch Dis Child 104: 340-347.

5. Rumsfeld JS, Alexander KP, Goff DC Jr, Graham MM, Ho PM, et al. (2013) Cardiovascular health: The importance of measuring patient-reported health status: A scientific statement from the American Heart Association. Circulation 127: 2233-2249.

6. Cheuk DKL, Wong SMY, Choi YP, Chau AKT, Cheung YF (2004) Parents' understanding of their child's congenital heart disease. Heart 90: 435-439.

7. Van Deyk K, Pelgrims E, Troost E, Goossens E, Budts W, et al. (2010) Adolescents' understanding of their congenital heart disease on transfer to adult-focused care. Am J Cardiol 106: 1803-1807.

8. Stout KK, Daniels CJ, Aboulhosn JA, Bozkurt B, Broberg CS, et al. (2019) 2018 AHA/ACC guideline for the management of adults with congenital heart disease: $A$ Report of the American College of Cardiology/American Heart Association Task Force on Clinical Practice Guidelines. Circulation 139: e698-e800.

9. Veldtman GR, Matley SL, Kendall L, Quirk J, Gibbs JL, et al. (2000) Illness understanding in children and adolescents with heart disease. Heart 84: 395-397.

10. Matley SL (1997) Understanding, beliefs, and behaviour: A study of children with congenital heart defects. Doctoral thesis, University of Leeds, Leeds, UK, 19-24.

11. Wang Q, Hay M, Clarke D, Menahem S (2011) Adolescents' drawings of their cardiac abnormality. Cardiol Young 21: 556-561.

12. Saidi A, Kovacs AH (2009) Developing a transition program from pediatric-to adult-focused cardiology care: Practical considerations. Congenit Heart Dis 4: 204-215.

13. Wang QF (2010) Adolescents' knowledge of their cardiac abnormality and its relationship with their cardiac related quality of life. Int Med J 40: 60-61. 